\title{
Problems of activity of measuring laboratories in the sphere of quality of soils and potential ways of their solution
}

\author{
A. Shovkovska \\ National Scientific Center "Institute of Soil Science and Agrochemistry named after O.N. \\ Sokolovsky »
}

The purpose. To analyze modern demands to measuring laboratories in the sphere of quality of soils, to determine problems in heading international demands to activity of such laboratories, and to offer possible methods of their solution. Methods. Analysis and systematization are used for determination of demands to activity of measuring laboratories set in normative and legislative baselines. Results. Basic legislative and normative deeds which put forward new, coordinated with international, demands to activity of measuring laboratories are analyzed. The basic problems on the way of their heading are taped and possible methods of their solution are offered. Conclusions. For recognition of competence at national and international levels measuring laboratory should organize the activity according to demands of international standard DSTU ISO/IEU 17025 with use of standard samples of soil and obligatory participation in interlaboratory comparisons of observed data.

Key words: measuring laboratories, accreditation, accuracy, results of measurement, standard samples of soil, quality of soils.

Introduction. The basis for the research, recommendations for producing are information that is obtained from the analytical laboratory measurements, and its accuracy and appropriate precision, which in turn depends on metrological provision affects the correct decisions on measures to improve quality and soil fertility. That is why the development of the field of soil, on the one hand, directly affects the development of metrological support in this area, and the other - depends on it.

At the present stage of development of the field of soil is characterized by globalization and the thrust of international cooperation. The same processes occur in metrological support in this area. This is, first seen in terms of preferred physical quantities characterizing the soil quality, in terms of SI. Second, a large number of national standards harmonized with international and European standards in the group 13.080 (according to SC 004) "The quality of the soil. Soil Science "- the level of harmonization of standards is $54 \%$ (152 of 283 standards) [1]. International direction of impact and the conditions of work and increases the competence requirements for analytical laboratories in the field of soil and control their condition.

Research purpose - to analyze the current conditions of the laboratories measuring the field of soil and control their condition, to identify the main problems and propose solutions.

Methods. Used methods of analysis and systematization.

Results. In order to adapt legislation in the field of metrology and metrology in the European and international, the Law of Ukraine "On metrology and metrological activity" [2], the provisions of which are based on the requirements of the directives of the International Organization of Legal Metrology OIML D1 "Key provisions of the law on metrology" (D1 OIML «Considerations for a Law on Metrology» [3]). Using directives D1 OIML allowed Ukraine to harmonize the Act with the relevant laws of the European Union. Therefore, a number of rules and regulations that have been regulated in the previous law of Ukraine "On metrology and metrological activity" and common used in metrological practice not included in the current Law of Ukraine, there is no such thing as certification of measuring laboratories.

Currently metrological centers that were previously carried out the certification, offering instead voluntary assessment and recognition of measurement capabilities of laboratories, the results of which provided assessment certificate and certificate for recognition of measurement capabilities. However, 
recognition of competences at national and international level measuring laboratory must undergo the accreditation procedure for compliance with the international ISO/IEC 17025 [4] to obtain internationally recognized certificates of accreditation. As of 2015 in Ukraine, 19 laboratories conduct tests to determine the characteristics of the soil, are required by DTR ISO/IEC 17025 and have the certificates [5].

DTR ISO/IEC 17025 specifies requirements for measuring laboratory management and technical requirements, among which are the requirements for personnel, premises and environmental conditions, equipment, and requirements for methods of measuring, assessing their suitability and accuracy of measurement [6].

However, there are some problems that prevent measuring laboratories to achieve full compliance with the requirements of this standard. First of all, outdated material and technical base of some laboratories that prevents obtaining high precision results and the implementation of national standards harmonized with international and European standards, limiting the competitiveness and access to international level.

Moreover, the necessary condition for effective activity measurement laboratories in the measurement of soil samples is the use of certified reference materials [7]. Requirements DTR ISO/IEC 17025 provides for the use certified reference materials to establish measurement traceability to SI units and internal quality control measurements. In addition, use the certified reference materials to control the quality of the results is regulated by a number of methods for determining standards for agrochemical characteristics of soils (about $15 \%$ of sub standards 13.080.10 "Quality of soil and soil science at all"). Now in Ukraine 1 State certified standard sample of soil, which was developed by the Center of the State Service of standard samples of soil that has been created at the NSC "ISSAR named after O.N. Sokolovsky ", together with NSC" Institute of Metrology "and 15 industry standard control samples developed "Derzhhruntohorona". But not all measurement laboratories in the measurement of soil samples using reference materials due to the fact that state and industry standard samples were tested recently, and this time the reference materials this level did not exist.

In addition to measuring laboratories that perform measurements in the field of state metrological supervision (in legally regulated metrology), to which the control of the environment, including control of soil is mandatory participation in inter-laboratory comparisons of measurement results. During the accreditation, part in inter-laboratory comparisons is also one of the main criteria for evaluating the competence of laboratories. Moreover, according to the documents of the National Accreditation Agency of Ukraine, environmental testing (including soil) are the main disciplines where mandatory participation in interlaboratory comparisons [8]. Unfortunately, in the area of control of soil inter-laboratory comparisons almost not held due to lack of appropriate programs and laboratories that could perform coordinator. To solve this problem, to develop a program of interlaboratory comparative measurements, the coordinator of this work may be National Scientific Center "Institute of soil sciences named after O. N. Sokolovsky "[9].

No less important is fact that the reporting of the measurement result should give a quantitative indication of the quality results so that you can correctly assess its reliability. Without such indications the measurement results is nothing to compare with each other or with reference values given in standards [10]. At the same time, as shown by the analysis of national standards of Ukraine on methods for determining the composition and properties of soil to characterize the accuracy of the method used around 20 different indicators. All this leads to confusion and misunderstanding as in the evaluation of the accuracy of the results and in the preparation of documents for accreditation of analytical laboratories. This situation is because the basic standards governing requirements for the development of standards for measurement methods, there is no single approach to the characterization of the accuracy of methods. Therefore, proper attention accuracy assessment when developing or updating method is not paid. Improving regulations Standardization of measurement methods, especially the process of assessing their accuracy, according to international standards DTR GOST ISO 5725 [11], will help improve the quality measurement methods in the field of condition monitoring and identification of the characteristics of soil, to simplify the process of assessing the accuracy of the results achieved unity 
approaches, including the international standards and requirements and thus achieve recognition of measurement other organizations.

The foregoing makes it possible to conclude that already made the first steps towards implementing international standards and international practices in metrology laboratories activity in the field of soil quality and control of their condition, but there are problems that limit competitiveness and investment attractiveness of analytical laboratories sector. The only way to solve them is to improve metrological support and organization of laboratories with international requirements, including the assessment of the accuracy of measurement, and mandatory participation in the program inter-laboratory comparative measurements. And given the fact that customers often important not only to obtain reliable measurement results, but the interpretation of these results and provide on the basis of their evidence-based recommendations to improve the quality and management of soils, it is expedient to create accredited laboratories in the leading scientific institutions.

\section{Conclusions}

At present, given the direction to international cooperation, it is important to confirm the results of measurements in the field of soil and control their condition, which may, subject to the laboratories carrying out analysis, requirements for the competence governed by DTR ISO/IEC 17025. That envisages obligatory participation in inter-laboratory comparisons of results of measurements and quality control measurements using standard samples of soil, and the ability to assess the accuracy of the results and methods in accordance with international standards. Therefore metrological support in the field of soil and control their condition requires output to a new level with the obligatory account international approaches as the organization of the laboratory, and to the evaluation of the accuracy of methods and results.

\section{Bibliography.}

1. List the basic regulations in the field of soil science, agricultural chemistry and soil protection / [ordered S. Baluk, M. Lazebna]. - Kharkiv, 2015. - 72 p.

2. On Metrology and metrological activity: law of Ukraine: [accepted June 5, 2014 № 1314-VII].

3. Considerations for a Law on Metrology : D1 OIML - Edition $2012-54$ p.

4. General requirements for the competence of testing and calibration laboratories (ISO/IEC 17025:2005, IDT): DTR ISO/IEC 17025:2006 - [Valid from 2007-07-01]. - Kiyv: Derzhspozhyvstandart, 2007. - 32 p. - (National Standard of Ukraine).

5. Shovkovskaya A.V. Laboratory Accreditation - a way to enhance analytical work in the field of soil / A.V. Shovkovskaya, M.E. Lazebna // Agrochemistry and Soil Science. - 2015. - № 84 - P. 141-144.

6. List of testing laboratories accredited for compliance DTR ISO/IEC 17025:2006 - Access to electronic pages : http://naau.org.ua/reyestr-akreditovanix-oov.

7. The problems of development and use of standard soil samples / S.A. Baluk, Y.V. Borodina, M.E. Lazebna, L.V. Tkachenko // Bulletin of Agricultural Science. - 2010 - № 2 - P. 11-15.

8. The concept of evaluating the competence of testing laboratories on the basis of participation in inter-laboratory comparative tests : ZD-08.01.21 : approved National Accreditation Agency of Ukraine 17.10.2011-6 p.

9. Lazebna M.E. Metrological support in sphere of quality of soils: demands, modern state and ways of development / M.E. Lazebna // Bulletin of Agricultural Science. - 2015 - № 11 - P. 53-56.

10. Guide to the expression of uncertainty in measurement / GUM: 1993, First edition, 1993 ISO : Geneva 1995 - Access to electronic pages : http://bipm.org/utils/common/documents/GUM.pdf

11. Accuracy (trueness and precision) of measurement methods and results (GOST ISO 5725) : DTR GOST ISO 5725:2005 -- [Valid from 2006-07-01]. - Kiyv: Derzhspozhyvstandart, 2006. - 334 p. - (National Standard of Ukraine). 